\title{
Mulheres e ecofeminismo: Uma abordagem voltada ao desenvolvimento sustentável
}

\section{Women and Ecofeminism: An Approach to Sustainable} Development

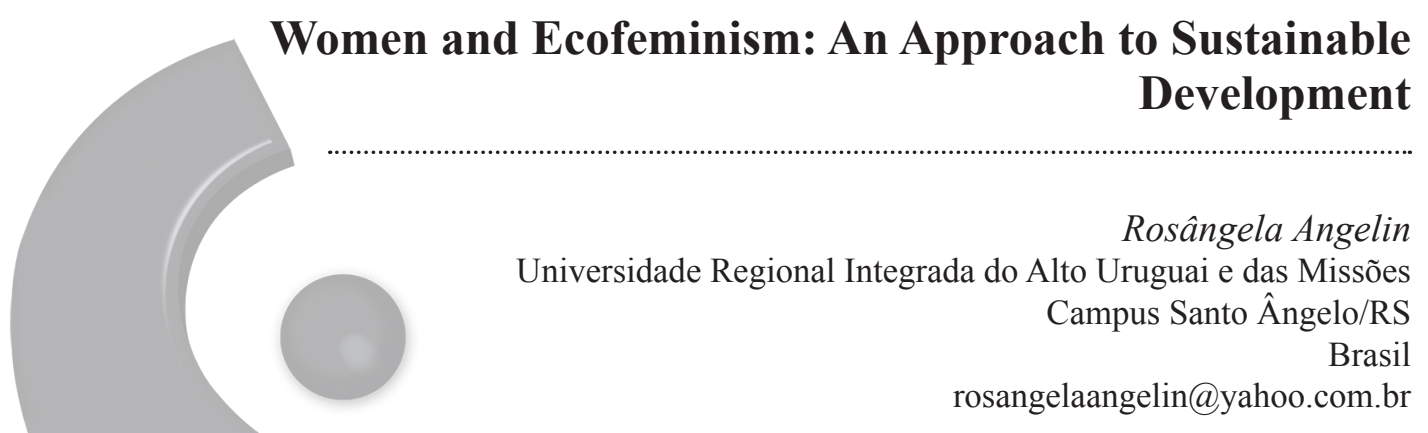

Recibido: 03/03/2017 Aceptado: 08/06/2017

Resumo: Atualmente, tanto o tema ambiental, quanto as teorias de desenvolvimento sustentável ocupam um lugar central nos debates de várias áreas do conhecimento, exigindo uma reflexão mais aprofundada acerca dos comportamentos humanos entre si e diante do meio ambiente natural. Diante disso, há que se considerar que, as sociedades baseadas no modo de produção capitalista apresentam uma enorme dificuldade de garantir um desenvolvimento humano, social e ambiental que seja sustentável e, ao mesmo tempo, tem avançado rumo a desumanização e a destruição do planeta. A partir do método de procedimento sócio-histórico-analítico e de uma abordagem feminista, o trabalho procura analisar a relação das mulheres com o meio ambiente, questionando-se se existe alguma relação entre exploração e dominação da natureza e dominação e subordinação das mulheres nas relações de gênero. Os estudos baseados nas teorias ecofeministas constatam que existe uma ligação consistente entre a exploração do meio ambiente natural e das mulheres, baseada em processos fundamentados no modo de produção 
capitalista e em relações humanas patriarcais, sendo que existe uma objetificação tanto das mulheres como da natureza. Isso demonstra que a proximidade entre as mulheres e ecossistema existe muito mais do que por um fator natural, mas sim pelas condições de poder impostas. Assim, frente a crise ambiental, as ideias e experiências de cuidado e solidariedade, vivenciadas pelas mulheres são válidas para apontar alternativas de mudanças voltadas ao desenvolvimento sustentável.

Palavras-chave: ecofeminismo, desenvolvimento Sustentável, modo de produção capitalista, mulheres, relações de gênero.

\begin{abstract}
Nowadays, both the environmental theme and sustainable development theories occupy a central place in the debates of several areas of knowledge, requiring a more in-depth reflection on human behaviors among themselves and the natural environment. In light of this, it must be considered that societies based on the capitalist mode of production present a great difficulty in ensuring human, social and environmental development that is sustainable and, at the same time, has advanced towards dehumanization and destruction of the planet.

Based on the method of socio-historical-analytical procedure and a feminist approach, this paper seeks to analyze the relationship between women and the environment, inquiring if there is any relation between exploitation and domination of nature and domination and subordination of women in the gender relations. Studies based on ecofeminist theories have found that there is a consistent link between the exploitation of the natural environment and women. This link is supported by processes based on the capitalist mode of production and on patriarchal human relations, since there is an objectification of both women and nature. This shows that the proximity between women and ecosystem is much closer than by a natural factor, but by the conditions of power imposed. Thus, in front of the environmental crisis, the ideas and experiences of care and solidarity experienced by women are valid in order to propose alternatives for changes aimed at a sustainable development.
\end{abstract}

Keywords: ecofeminism, sustainable development, capitalist mode of production, women, gender Relationships.

\title{
Introdução
}

A realidade do planeta terra é alarmante. Catástrofes naturais se tornam cada vez mais presentes frente aos efeitos do aquecimento global, problemas relacionados ao acesso à agua, poluição do ar, da água, da terra e, o consequente aumento de doenças. Este cenário tem tido influência decisiva do modo de produção capitalista, baseado na descomedida exploração, geração e comercialização de riquezas. Diante da incontestável crise 
ambiental que assola a humanidade e da preocupação com seus efeitos para a vida nas mais diversas formas, teorias de desenvolvimento baseadas em políticas e ações sustentáveis são temas centrais de debates. Por conseguinte, tal cenário remete a análise das relações e comportamentos humanos baseados em relações de poder que estão gerando desumanização e destruição ambiental.

Embora Estados (quais estados?) tenham positivado normas e legislações, incluindo a tutela ambiental no rol de direitos fundamentais de suas Constituições, bem como investido em campanhas focadas na proteção ao meio ambiente natural, estas ações não estão apresentando os efeitos almejados, em especial, porque os modelos de desenvolvimento ditos sustentáveis encontram-se baseados em premissas antropocêntricas. Os problemas ambientais que assolam a humanidade são sistêmicos e, portanto, interligados e interdependentes diante de outros fatores como a economia e a forma de relações humanas existentes. Neste contexto, encontra-se o foco da análise desta pesquisa, que procura relacionar as categorias mulheres, ecofeminismo e desenvolvimento sustentável.

As mulheres tem sido as mais atingidas com as crises ambientais e, ao mesmo tempo, possuem uma história de vivências muito próximas ao cuidado com os ecossistemas, diferente do que se pode constatar da maioria do público masculino. Diante disso, o âmago motivador desta pesquisa encontra-se em buscar explicações, a partir do enfoque das teorias ecofeministas e da redistribuição econômica, da relação existente entre exploração e dominação do meio ambiente natural e a dominação patriarcal geradora de subordinação das mulheres nas relações de gênero e, como isso tem se configurado no desenvolvimento das sociedades, em especial em questões voltadas para o desenvolvimento sustentável.

\section{Mulheres, natureza e relações de poder}

A história das mulheres tem sido velada no decorrer de milênios e mantida à margem. Nos últimos períodos, em especial, depois do advento dos Movimentos Feministas, a recuperação da história das mulheres tem conquistado espaço em estudos científicos, tendo como aporte para reconstruir as histórias das mulheres várias áreas do conhecimento. Dentro destes estudos, se faz mister trazer a tona a relação das mulheres com a natureza, vista como espaço de vivência humana e manutenção da vida, bem como tem sido utilizada no discurso de justificativa para a opressão das mulheres. 
Embora a proximidade das mulheres com o meio ambiente natural tem sido um argumento para justificar relações de poder, como será tratado mais adiante, é evidente a proximidade desenvolvida entre ambas, em decorrência de diversos fatores, como o cuidado com a vida humana, o qual exigia um conhecimento mais detalhado da natureza, a fim de garantir o alimento e recursos utilizados para a cura de doenças. Porém, diante desta constatação, é importante não relativizar e, ao mesmo tempo, universalizar a proximidade entre mulheres e natureza, a fim de não se promover a naturalização das identidades femininas, baseadas em posicionamentos deterministas. Muito pelo contrário; é preciso se ter presente que as identidades humanas jamais são fixas, mas contingentes e transitórias, construídas a partir de vivências e processos históricos que assumem aspectos conscientes e também inconscientes, o que tornam as identidades inconclusas e mutáveis (Hall, 2005, p. 39).

Ao se analisar a história da humanidade, constata-se nos últimos períodos, um movimento constante e nada ingênuo de fixar e naturalizar identidades femininas e masculinas, afirmando-se em aspectos biológicos dos corpos que são diferentes. Assim, nesta primeira parte da pesquisa será analisada a relação das mulheres com a natureza e como essa proximidade foi sendo utilizada nas relações de poder e construção das identidades femininas.

A evidência primeira da proximidade das mulheres com o meio ambiente natural é apresentada em descobertas arqueológicas e traz a tona a figura da Deusa, representando a mãe terra. Para a mitologia grega, todo o universo foi criado por Gaia, a Mãe Terra. Outras cultural e religiões pagãs antigas, como Vikings e Celtas, também cultuavam deusas, destacando relações de proximidade destas com a natureza, em especial no que se referia ao poder da fertilidade. A socióloga e jurista, Riane Eisler, desenvolve estudos voltados para releituras da arqueologia, transitando, ao mesmo tempo pelas áreas da antropologia, sociologia, história, arte e economia, a fim de situar as mulheres nas relações de gênero desde os primórdios da história. Seus estudos tem demonstrado o culto pelo corpo da mulher como um local mágico de vida, relacionando-o com fatos da natureza, como, por exemplo, corpos que sangravam de acordo com a lua ou então, corpos que, assim a terra, geravam vidas e alimento para alimentar estes seres (Eisler, 1996, p. 39-40). Por conseguinte, é compreensível a relação criada entre mulheres e natureza, assim como sua veneração, as quais têm sido constatadas frente a indícios arqueológicos e correntes teóricas da própria antropologia.

A filósofa e feminista francesa, Elisabeth Badinter, desenvolveu estudos publicados na década de 1980, baseados na análise de padrões biológicos, 
comportamentais e culturais das relações firmadas entre mulheres e homens. Ela ressalta que, embora as mulheres tenham sido consideradas mais fracas fisicamente que os homens e, portadoras de desequilíbrio de humor devido a menstruação, o que a tornava naturalmente submissa aos homens, que eram seres mais fortes, perspicazes, equilibrados, corajosos, mais recentemente, tanto antropólogos, quanto primólogos começaram a questionar esta suposta inferioridade das mulheres em relação aos homens. Destas novas pesquisas surgiram explicações interessantes. Uma delas está baseada no fato de que, por as mulheres serem genitoras e terem como tarefa alimentar e cuidar de sua prole, enquanto os homens assumiam a tarefa de providenciar o alimento proteico, exigia delas muita inteligência e agilidade no trabalho de coleta de frutos e cereais, pois necessitavam estar atentas e serem eficazes diante dos perigos do entorno. Elas eram desafiadas a manter uma atenção constante frente à necessidade de proteger e alimentar sua prole, bem como de distraí-la e ensinar-lhes como se portar diante do mundo (Badinter, 1986, p. 37). Para Tanner, as mulheres coletoras tiveram uma contribuição muito significativa na manutenção da espécie humana, sendo que a prole de mães inteligentes e ágeis o suficiente para conseguir e partilhar alimentos com eles tinha uma vantagem evolutiva mais significativa (Tanner apud Eisler, 2007, p. 120). Tais constatações apresentam argumentos de desconstrução da teoria de que as mulheres sempre foram mais frágeis que os homens.

Outro aspecto trazido por Badinter denota a importância das mulheres nos primórdios da humanidade e sua relação próxima com a natureza, a destacar o surgimento da agricultura, que teria sido uma invenção das mulheres, a partir do exercício da coleta de alimentos. A partir desta atividade elas teriam passado a observar que as sementes que caiam no solo germinavam e produziam alimento, tendo sido elas as que começaram a reproduzir de forma artificial tal procedimento (Badinter, 1986, p. 59-60). Eisler contribui com este posicionamento, quando chama a atenção para mitos religiosos antigos que acabam atribuindo a criação ou invenção da agricultura a deusas, trazendo como exemplos, a deusa egípcia Ìsis e a deusa Ninlil retratada nas tábuas mediterrâneas. Com o fim da vida nômade, as atividades da agricultura passaram a ser divididas com os homens (Eisler, 2007, p. 121).

Alícia H. Puleo, professora de Filosofia Moral e Política na Universidade de Valladolid (Espanha), realiza estudos voltados para o ecofeminismo e a desnaturalização da mulher como o gênero mais próximo do meio ambiente natural. Ela retoma pesquisas desenvolvidas por François Poulain de la Barre, o qual afirma que as sociedades pré-históricas viviam relações mais 
igualitárias, embora existisse a divisão de tarefas entre homens e mulheres. Mesmo apresentando a tese da proximidade maior das mulheres com a natureza, o autor toma o cuidado de elucidar que os valores femininos foram forjados e deformados pela educação vivenciada em processos de relações sociais. Ele buscou provar que as mulheres são, e sempre foram dotadas de inteligência e, por conseguinte, merecedoras de reconhecimento e respeito, destacando o conhecimento das mulheres camponesas que, ao se dedicarem ao cultivo da terra, desenvolveram capacidades de previsões meteorológicas mais acertadas do que os próprios astrólogos, assim como, elas têm conhecimentos medicinais que muitas vezes se sobrepões e são mais eficazes que as receitas disponibilizadas por médicos com titulo (Puleo, 2013, p. 327-328).

O rememorar e o reconhecer a história das mulheres denota a importância que elas tiveram na história da humanidade, embora grande parte dessa história tenha sido negligenciada e, muitas vezes esquecida. Tanto Eisler, quanto Ruether chamam a atenção que, mesmo diante do elevado poder que as mulheres tinham nos períodos paleolítico e neolítico, não existem elementos que comprovem a existência de sociedades matriarcais, uma vez que as evidências encaminham-se para o entendimento de que nestas sociedades as relações humanas eram de parceria e cooperação, embora existisse a divisão sexual do trabalho (Ruether, 1993, p. 72; Eisler, 2007, p. 67-68). Chegou um momento na história que essa harmonia social foi sendo alterada por fatores como deslocamentos territoriais causados por catástrofes naturais, as quais geraram destruição e fome, bem como por ocupações territoriais de povos que cultuavam deuses masculinos. Estas influências contribuíram para a organização social baseada na hierarquia, com conotações autoritárias e masculinas demonstradas, em especial, pela substituição do culto das deusas para a adoração monoteísta de um deus masculino, o que serviu de fundamento para a cultura judaico-cristã, que mais tarde se desenvolveria (Ruether, 1993, p. 50-51). Diante disso, as guerras e a violência passaram a ser uma constante nas sociedades, substituindo a cultura de parceria para uma cultura de dominação (Eisler, 2007, p. 95).

As mudanças religiosas de substituição da deusa por um deus monoteísta aprofundaram as relações de dominação. O cristianismo, como uma religião patriarcal baseada na trindade masculina Pai, Filho e Espirito Santo aprofundou ainda mais a dominação masculina, proibindo o culto à deusas e afastando a sociedade ocidental do culto à natureza, desenvolvido até então pelas religiões pagãs. O teocentrismo cedeu lugar para o antropocentrismo, por decorrência da ascentção das artes, da ciência e 
da filosofia que seguiram um caminho oposto da teologia cristã, gerando instabilidade no poder da igreja católica. Para reconquistar o prestígio que estava se perdendo, a igreja católica aliou-se ao poder dominte e criou os Tribunais da Inquisição que perseguiam, em especial, mulheres camponeseas, sob a desculpa de que elas tinham pacto com o diabo e eram culpadas por toda a sorte de coisas ruins que aconteciam, evidenciando uma perseguição de conotação religiosa e política, mas também sexual (Ehrenreich; English, 1984, p. 10). Embora os dados não sejam precisos, acredita-se que cerca de 9 milhões de pessoas passaram pelo processo dos Tribunais da Inquisição, sendo acusadas, julgadas e mortas. Mais de 80\% dessas pessoas eram mulheres, crianças e moças (Menschik, 1977, p. 32). As mulheres perseguidas e mortas eram conhecidas como bruxas. Elas eram parteiras, médicas e enfermeiras sem título, que traziam consigo e aplicavam conhecimentos milenares envolvendo plantas mediciais utilizadas para curar doenças das pessoas de suas comunidades. Estas atividades lhes presenteavam com um elevado reconhecimento social e respeito, causando desconforto, em especial na igreja patriarcal que, de todas as formas, queria impôr o culto a um deus masculino. Essas mulheres eram vistas como simbolo do mal e relacionadas com a natureza e, portanto, portadoras do poder de provocar doenças, tempestades, pestes e matar crianças. Eram consideradas desordeiras e, como a natureza em desordem, era preciso controlá-las (Gebara, 1997, p. 10). ${ }^{1}$

O breve relato do processo de mudanças identitárias no decorrer da história da humanidade envolvendo mulheres ocorreu antes da ascensão do modo de produção capitalista, mas foi intensificado com esse que teve atuação decisiva na inferiorização, opressão e submissão das mulheres. Com o advento do modo de produção capitalista, as diferenças e desigualdades nas relações de gênero intensificaram-se, reforçando o papel estratégico das mulheres no espaço privado, condição esta vinculada à natureza biológica delas, enquanto aos homens era reconhecido o papel de vital provedor do lar. O trabalho das mulheres no mundo privado era considerado um trabalho executado por amor e, portanto, gratuito, servindo estrategicamente para reduzir os custos do salário dos homens, já que neste caso, os empregadores não teriam o compromisso de pagar pela prestação de serviços domésticos.

Em relação a dominação da natureza pelos seres humanos é importante destacar os períodos da Renascença (século XVI) e Revolução Científica (século XVII), que reduziram a natureza a formas racionais, sendo que os homens passam a se denominar como os grandes conhecedores da natureza, suscitando a ideia de expansão e manipulação desta para as ditas necessidades humanas (Ruether, 1993, p. 75). 
Tanto a primeira Guerra Mundial quanto a segunda contribuíram para abalar esta organização dos papéis patriarcais capitalistas nas relações de gênero. Os homens foram para os campos de batalhas e, diante deste novo cenário, o trabalho feminino foi requisitado para suprir as vagas deixadas pelos homens nas fábricas e indústrias. Vale destacar que, embora elas exercessem as mesmas tarefas que os homens, os salários eram mais baixos e elas eram obrigadas a manter, concomitantemente, o cuidado com a casa, a prole e as pessoas doentes, ressaltando-se a ideia de que o papel do cuidado e das obrigações domésticas era de cunho natural das mulheres. Embora a sobrecarga de trabalho seja evidente, as mulheres ocuparam este espaço da vida pública e tiveram êxito nas atividades desenvolvidas até então pelos homens, iniciando um processo de empoderamento e ressignificação de suas identidades, bem como ocorreu um despertar na busca por melhores condições de trabalho (Perrot, 2007, p. 144).

Este novo cenário corroborou em prol dos Movimentos Feministas, embalada na teoria da feminista francesa Simone de Beauvoir (1968), de que não se nasce mulher, mas sim, torna-se mulher, derrubando as argumentações voltadas para o destino biologicamente determinante das identidades femininas. A antropóloga latino-americana e professora da Universidade Nacional Autônoma do México, Marcela Lagarrde de los Ríos, que desenvolve com estudos voltados para os Movimentos Feministas e as condições de vida das mulheres e corrobora diretamente com as ideias de Beauvoir, quando afirma ser a cultura de um povo a dimensão da existência das pessoas e, para tanto, a determinante da existência e concepções de mundo, sendo isso tudo uma construção histórica. Para a autora, a cultura é resultado da "[...] distinción humana resultante de las diversas formas de relación dialéctica entre las características biológicas y las características sociales de los seres humanos" (Lagarde y de los Ríos, 2011, p. 57). ${ }^{2}$

No caso das identidades das mulheres, o que as relações patriarcais têm imposto como natural é a ideia de que as características biológicas (menstruar, engravidar, ter filhos, amamentar, entrar na menopausa) definem as mulheres

2 As afirmações acima feitas, não se colocam ao lado do relativismo cultural que justifica os comportamentos das pessoas a partir de sua cultura e, portanto, intocável. Eagleton salienta que as pessoas não são criaturas inteiramente culturais e, portanto, não se pode absolutizar uma cultura, relativizando-a em relação ao mundo. Para o autor, existem algumas necessidades e especificidades que são naturais a todos os seres humanos, independentes da cultura na qual foram criados (Eagleton, 2005, p. 134; 144). 
e, portanto, estas são parte da natureza, devendo seguir as leis dela. Nesta concepção, as mulheres seriam “[...] débil por naturaleza, obstinada y Dulce por naturaleza, maternal por naturaleza, estúpida por naturaleza, y también pérfida y amoral por naturaleza", não sendo consideradas mulheres normais as que fujam destes padrões (Basaglia apud Lagarde y de los Ríos, 2011, p. 56, Nota de Rodapé n. 1). Encarna Sanahuja Y1l, professora de Pré-história da Universidade Autônoma de Barcelona, explica em seus estudos que esta naturalização dos papéis femininos nas relações sociais contribui para a discriminação e dominação das mulheres, sendo resultado de uma ideologia androcêntrica que supervaloriza o controle exercido pelos homens ao meio ambiente e as tecnologias, "[...] negando así la sujeción humana a la naturaleza y también la materialidad del cuerpo" (Y11, 2007, p. 88).

Processos históricos seguem sendo capazes de justificar a exclusão das mulheres, sua dominação e inferioridade com bases no argumento da natureza feminina. Por isso, "Es imprescindible desarrollar la consciencia de ser históricas y, al vivir, ser sujetas de la historia". Despojarnos de los ropajes metafóricos que nos animalizan e nos homologan con la tierra y asumir nuestra condición identitaria de humanas" (Lagarde y de los Ríos, 2011, p. 31). Para a cultura capitalista patriarcal, tanto as mulheres como a natureza são objetos de exploração justificada e naturalizada. É para contestar essas ideias que o feminismo, através de correntes ecofeministas, traz novos argumentos.

\section{Ecofeminismo e Desenvolvimento Sustentável}

Ao se trabalhar a questão das mulheres e sua relação com a natureza rumo a um desenvolvimento sustentável, Eisler pondera que na atualidade até mesmo o meio ambiente natural parece estar se posicionando contra a cultura androcêntrica e, isso pode ser constatado através da escassez dos recursos naturais, bem como pelas consequências da poluição e da destruição ambiental. É importante se ter presente que tal constatação não significa um posicionamento contra o desenvolvimento tecnológico, mas sim contra o uso de tecnologias que tem exercido dominação e conquista sobre a natureza, as mulheres e/ou sobre outros seres humanos (Eisler, 2007, p. 243).

O despertar ecológico seguido de uma consciência ambiental de que é necessário rever a relação com o meio ambiente natural tem estado em voga nas últimas décadas. É possível afirmar que estes valores de preservação e cuidado estão ligados a figura da deusa que fora cultuada por milênio pelos povos pagãos, proporcionando um debate voltado aos valores do cuidado e da solidariedade, reservados culturalmente, especialmente, às mulheres. 
Revista Universidad en Diálogo • Vol. 7, N. ${ }^{1}$ 1, Enero-Junio 2017, pp. 51-68

ISSN 2215-2849 • EISSN: 2215-4752

DOI: http://dx.doi.org/10.15359/udre.7-1.3

Conforme já mencionado, a proximidade das mulheres com a natureza corroborou com a perspectiva de exploração destas, assim como se explora o meio ambiente natural, sob a justificativa de que ambas se encontrarem num nível inferior ao dos homens.

A partir deste contexto, desenvolveu-se, dentro dos Movimentos Feministas contemporâneos uma corrente denominada de ecofeminismo. Barbara Holland-Cunz, professora de Ciência Política na Freie Universitat de Berlin (Alemanha), volta-se para estudos sobre as mulheres desde uma perspectiva sociológica e da filosofia da natureza, observando que as teorias feministas se configuram na história como minoria e, dentro desta teoria minoritária, encontra-se a teoria ecofeminista, que também se apresenta como uma minoria entre as demais teorias feministas. A corrente ecofeminista se configura no enfoque em conectar uma comunicação sócioteorica, envolvendo a relação entre a natureza e os sexos (Holland-Cunz, 1996, p. 29-30). Maria Mies e Wandana Shiva evidenciam a perspectiva de superação conjunta da submissão e exploração das mulheres e da hierarquia que foi criada dos seres humanos sobre o meio ambiente natural, ressaltando a importância da ecologia e do feminismo: "Ecologismo y feminismo [...] simbolizan la búsqueda de condiciones de vida más igualitárias entre los seres humanos que, al mismo tiempo, sean respetuosas con el medio ambiente y todas las formas de vida" (Mies; Shiva, 1995).

O despertar do ecofeminismo se deu ao final da década de 1970, a partir de movimentos sociais de mulheres, movimentos pacifistas e também de movimentos ambientalistas que se uniram para criticar a construção de usinas nucleares. Ao se firmar, o movimento ecofeminista trouxe à tona o debate envolvendo a relação entre a exploração e a submissão imposta pelo poder do patriarcado sobre a natureza, as mulheres, bem como sobre os povos estrangeiros (Mies; Shiva, 1995, p. 23). Por ser um movimento que se baseia na compreensão e análise crítica dos fatores acima mencionados, o ecofeminismo possibilita uma nova forma de tomada de consciência diante da falta de valorização com o cuidado que deve ser dispensado com a natureza e os seres humanos, sob uma forte crítica dos estereótipos gerados pelo patriarcado, evidenciando a ligação profunda entre a economia, a crise ecológica e os estilos de vida da humanidade (Puleo, 2013, p. 10).

Para compreender melhor as ideias do ecofeminismo, é importante ter presente que ele abrange uma diversidade de formas e expressões dentro dos Movimentos Feministas e está dividido em três principais tendências (Puleo, 2002, p. 37-39): 
a) Ecofeminismo clássico. Esta corrente do ecofeminismo se baseia na busca de elementos para desnaturalizar o papel das mulheres diante dos mecanismos de legitimação apregoados pelo patriarcado, bem como em denunciar a obsessão pelo poder desenvolvidas pelos homens, que tem gerado guerras e destruição do planeta. Assim, através de uma ética feminista voltada para proteger todos os seres vivos, esta corrente se opõe a agressividade masculina, tida como uma predisposição natural para a competição e destruição e, ao mesmo tempo ressalta as características femininas igualitárias e maternais como exemplo para o pacifismo e da conservação do meio ambiente natural;

b) Ecofeminismo espiritualista do Terceiro Mundo. Esta corrente é oriunda dos países do sul, influenciada pelos princípios religiosos asiáticos de Ghandi e pela Teologia da Libertação, existente nos países latino americanos. A teoria está baseada na argumentação de que a forma como a sociedade foi se desenvolvendo, sob o prisma de parâmetros patriarcais de poder, tem gerado processos de profunda violência contra as mulheres e a natureza. Por isso, sua posição está alicerçada na crítica da dominação patriarcal, sexista, racista, elitista e antropocêntrica da sociedade, defendendo a tendência cosmológica e protetora das mulheres para com a natureza;

c) Ecofeminismo construtivista. Por fim, esta corrente não se relaciona com o essencialismo, nem com os aspectos religiosos e espirituais das correntes anteriormente expostas, muito embora se filie a crítica feita ao racismo, antropocentrismo e imperialismo. O ecofeminismo construtivista posiciona-se contra a defesa de que a relação profunda existente entre a maioria das mulheres e natureza esteja ligada a características próprias do sexo feminino. No lugar disso, ressalta que esta ligação se origina a partir das responsabilidades de gênero que as mulheres assumem na economia familiar, criadas a partir da divisão do trabalho, bem como de aspectos da distribuição da propriedade e do poder. A partir disso, essa teoria aponta para a necessidade da existência e do cultivo de outras formas de relação de gênero e também de relações com o meio ambiente natural.

Diante das correntes do ecofeminismo apresentadas, Puleo (2002) evidencia a debilidade teórica defendida nas duas primeiras tendências, as quais tendem a reafirmar estereótipos femininos na sociedade e, filia-se ao ecofeminismo construtivista. Mesmo assim, acredita que se esta corrente 
considerasse a mística e a religiosidade teria mais êxito, pois essas são características mobilizadoras para as mulheres. Casares (2012, p. 289) ressalta que, aproximar os discursos espirituais e o materialismo cultural ainda é um grande desafio, lembrando que tanto Wandana Shiva, quanto o teólogo brasileiro Leonardo Boff acreditam na importância da religiosidade para a proteção do meio ambiente, baseada em premissas éticas de sustentabilidade, uma vez que a religiosidade traz consigo princípios mais voltados para a ética da responsabilidade (Casares, 2012, p. 289).

Trabalhar com ética e responsabilidade diante dos fundamentos geradores da exploração da natureza e da subjugação de povos, reconhecendo sua proximidade, é de elevada importância. O meio ambiente natural e as mulheres têm sido considerados coisas úteis pelo e para o desenvolvimento do capitalismo patriarcal, quer como objetos de consumo, ou como meios de produção e/ou exploração. Embora o patriarcado capitalista se declare autônomo, ele depende diretamente dos recursos naturais e do trabalho das mulheres (Puleo, 2013, p. 287). Ao mesmo tempo, este modo de produção tem se demostrado intolerante frente a outras espécies, a outros seres humanos e, também a culturas que são diferentes, buscando dominálas. A realidade é que sempre que se debate o modelo econômico de desenvolvimento de uma sociedade, ocorre o inevitável encontro com questões sobre os limites do ecossistema e as relações humanas (Puleo, 2013 , p. 10). Por isso que os movimentos ecofeministas e os movimentos ecológicos convergem com o intuito de propor novas maneiras para garantir uma melhor convivência no planeta, ou seja, um desenvolvimento sustentável, se opondo, por conseguinte, a dupla forma de exploração capitalista e patriarcal que afeta o ecossistema e as mulheres.

Definir desenvolvimento sustentável no modo de produção capitalista é uma tarefa complexa. Embora a sociedade tenha se empenhado em viabilizar na prática este conceito, acaba-se deparando com os limites impostos pelos moldes de desenvolvimento econômico, que justifica suas ações sobre e contra a natureza, com base nos padrões de consumo e promoção de novos empregos. A perspectiva liberal defendida pela maioria dos Estados evidenciando o desenvolvimento econômico acima de tudo, tem gerado espaços de profundas críticas a toda e qualquer legislação protetiva ao meio ambiente, que são tidas como um entrave para o desenvolvimento. Só que, por outro lado, estes mesmos Estados acabam adotando um discurso ambientalista, embasado em ações esporádicas que venham a justificar suas atitudes destrutivas e que possam livrár-los da efetiva responsabilidade de proteção e preservação da natureza. É nestas bases de desenvolvimento que 
atualmente se encontram o meio ambiente e as mulheres e, a contribuição da teoria ecofeminista é no sentido de recuperar e valorizar o ecossistema e as mulheres, que "[...] foram relegadas pelo sistema patriarcal e particularmente pela modernidade a serem força de reprodução de mão de obra, 'ventres benditos', enquanto a natureza tornou-se objeto de dominação em vista do crescimento do capital" (Gebara, 1997, p. 10).

As mulheres tem sido as mais afetadas que os homens diante das crises ambientais, fato este que não evidencia a necessária e naturalizada relação dessas com a natureza, senão a existência de relações de poder dos homens sobre as mulheres. Assim, as mulheres acabam sendo as mais afetadas com as crises e a destruição ambiental, sendo as primeiras a serem afastadas dos bens produzidos pelo meio ambiente, gerando sobre seus corpos e suas vidas as ameaças impostas pelo desequilíbrio ecológico (Gebara, 1997, p. 14-16). Por esse motivo é que as mulheres estão mais preocupadas e atentas com a saúde de suas família e, diante das crises ambientais, são as primeiras a reivindicarem água potável, alimentos saudáveis e condições de vida que sejam salubres. Neste debate, a filósofa e feminista estadunidense, Nancy Frase, destaca que os corpos das mulheres foram utilizados e subjugados pelas relações patriarcais de poder e pelo capitalismo que, a partir de suas diferenças biológicas e da naturalização de sua submissão, as utilizou como força de trabalho barata, explorando-as, assim como fez e segue fazendo com os recursos naturais. Por receberem menores salários que os homens e, frente ao elevado índice de desemprego e trabalho informal, as mulheres tem sido as mais prejudicadas e injustiçadas frente à distribuição de recursos naturais. Este retrato é mais evidente nos grupos de mulheres pobres, marginalizadas e distantes de direitos de cidadania, situação esta que segue em pauta nos Movimentos Feministas e de mulheres, com a finalidade de garantir qualidade de vida e equidade de gênero. É nesse mesmo espaço e com esse intuito que se encontram os movimentos ecofeministas (Fraser, 2010).

Fatos históricos demonstram que, na atualidade, a partir da derrocada de países tidos como socialistas/comunistas, ocorreu um fortalecimento do ideário capitalista e da busca de se vislumbrar a origem das desigualdades sociais, perdendo-se de vista que estes problemas têm uma origem comum, ou seja, a má distribuição de renda. Nem mesmo os movimentos feministas escaparam desta influência. Segundo Fraser, estes movimentos voltaram-se na atualidade mais para o reconhecimento das diferenças de gênero, do que para a má redistribuição de renda (Fraser, 2010, p. 168). Os movimentos feministas têm sido redirecionados para outro aspecto, ou seja, mais voltados 
para o imaginário culturalista identitário. Não que isso não seja importante, mas, voltando-se incisivamente para as questões identitárias (Fraser, 2007b, p. 293). Não que as demandas identitárias não sejam importantes, mas, sob o enfoque de Fraser e dos movimentos ecofeministas, fica clara a necessidade de não se abolir das lutas a perspectiva de redistribuição econômica, uma vez que a exploração capitalista patriarcal que subjuga as mulheres, também as afasta do acesso à bens e recursos, negando-lhes o reconhecimento de membros integrais da interação social.

Para Fraser, tanto a estrutura de classes, quanto o status social são obstáculos que impedem a participação paritária e propõe a análise dos conflitos sociais de forma dualista: considerando, de um lado a redistribuição de renda e, do outro o reconhecimento de um novo status social ocasionado pelo empoderamento da redistribuição (Fraser, 2007a). A esta teoria se encaixa a situação das mulheres como uma coletividade bivalente e injustiçada pela má distribuição de rendas e, pelo reconhecimento cultural equivocado de suas identidades. Frente a isso, a autora aponta soluções para ambas as injustiças denominadas de remédios. Estes estão voltados para um processo de reorganização das relações de trabalho e, também do acesso a participação democrática nas decisões do Estado. Isso tudo ocorre conjuntamente com uma reavaliação de identidades estereotipadas das mulheres, rumo ao respeito à diversidade cultural (Fraser, 2011).

As ideias de Fraser podem ser acolhidas na luta ecofeminista. Os referidos remédios estariam relacionados a uma atuação direta do Estado a partir de medidas afirmativas, as quais tem o papel de corrigir injustiças, porém, não são capazes de modificar as estruturas que as formam (como ocorre nos Estados liberais diante de políticas ambientais), bem como através de outro tipo de medidas mais pontuais, ou seja, medidas transformativas capazes de priorizar a reestruturação das situações que geram os problemas. Enquanto as medidas afirmativas não são capazes de abolir as diferenças de classe, nem os fatores originários causadores dos problemas, as medidas transformativas seriam capazes de minar as diferenças de classe a partir da redistribuição econômica (Mattos, 2004, p. 148, nota de rodapé n. 09), podendo gerar, por conseguinte, uma nova visão de desenvolvimento social sustentável.

Mesmo diante das diversas interpretações e vertentes do ecofeminismo, estas teorias tem contribuído muito como um ponto de encontro entre feminismo e ecologia, destacando-se que ambas têm um ponto básico de partida, ou seja, a preocupação com a sustentabilidade humana, social e ecológica, baseadas não apenas em premissas de sobrevivência, mas 
também de equidade e qualidade de vida que não serão alcançadas se não for observado o cuidado da vida, ajustando as questões envolvendo o desenvolvimento econômico no ritmo biológico e ecológico (Puleo, 2013, p. 286-287). Diante disso, se faz urgente reelaborar o conceito de cidadania, englobando a cidadania ambiental a ser desenvolvida nos espaços públicos e privados, construindo a perspectiva de desterritorialização ecológica e fazendo um chamado coletivo para o comprometimento frente as relações de desigualdades entre os países do sul e do norte (Puleo, 2002, p. 270271). Esta preocupação voltada para tanto para a natureza, quanto para as injustiças sociais, entre elas as cometidas contra as mulheres, sempre se fizeram presentes nos ideais ecofeministas.

\section{Consideraçães finais}

Transformar el modelo androcéntrico de desarrollo, conquista y explotación destructivos implica tanto asumir una mirada empática sobre la Naturaleza como un análisis crítico de las relaciones de poder

(Puleo, 2002)

A pesquisa procurou trabalhar, a partir de uma abordagem feminista, questões envolvendo mulheres, ecofeminismo e desenvolvimento sustentável, no intuito de desvelar uma suposta relação natural entre as mulheres e a natureza, bem como testar a premissa da existência de uma relação próxima entre a exploração e dominação da natureza e das mulheres nas relações sociais. A priori, constatou-se que as identidades fazem parte de processo de construções históricas, baseados, principalmente em relações de poder. No caso da análise das identidades femininas, há que se ter presente o fato que os corpos femininos e masculinos se apresentam biologicamente diferentes, com necessidades peculiares a cada sexo. Ser diferente não é um problema para as questões identitárias. O problema está quando as diferenças, neste caso as biológicas, são motivos geradores de desigualdades e privilégios para alguns, como aconteceu com as mulheres, a partir da sua suposta naturalização da maternidade e do cuidado, situações essas intensificadas pelas responsabilidades que a maioria das mulheres possui na economia familiar. Por isso, o estudo chama a atenção para o cuidado que se deve ter ao afirmar a relação natural de proximidade entre mulheres e meio ambiente, a fim de não corroborar ainda mais na reprodução e no reforço da naturalização da submissão e exploração das mulheres. 
Os movimentos ecofeministas, ao que pese suas especificidades, são importantes para o debate central de denúncia a exploração das mulheres e da natureza pelo capitalismo patriarcal, a partir de sua objetificação e submissão ao poder dominante. Ao mesmo tempo, esses movimentos ressaltam a necessidade de superar estas formas de opressão como um importante pressuposto para a viabilização do desenvolvimento sustentável, o qual deve abranger um olhar sistêmico, não considerando somente questões econômicas, mas também a construção de relações humanas saudáveis que estejam voltadas para a proteção ao meio ambiente natural. Essa questão é de urgência, em especial pelo fato das consequências nefastas da destruição ambiental, estarem embasadas no principal argumento de satisfazer as necessidades capitalistas, atingindo, em especial, as mulheres pobres que sobrevivem a partir de uma economia de subsistência. Elas são as primeiras a sentirem os reflexos da diminuição da qualidade de vida, causadas pela escassez de recursos naturais ou pela destruição e poluição ambiental. Garantir que as mulheres tenham um acesso mais equitativo à renda através da redistribuição econômica, é uma forma de garantir um novo status social para elas e, com isso, uma possibilidade maior de participação das decisões do Estado, o que poderia configurar novas formas e perspectivas de governar, de se relacionar com as pessoas e com a natureza. Porém, se a redistribuição econômica não estiver acompanhada de valores humanos como o cuidado, a solidariedade e a parceria entre as pessoas, poderá apenas estar se reproduzindo, de maneira mais ampliada, os moldes de sustentabilidade liberais que, comprovadamente, não resolvem o problema estrutural da crise ambiental e humana enfrentada atualmente.

Fato é que o capitalismo patriarcal tem se demonstrado incompatível e incapaz de arcar com as exigências de um desenvolvimento sustentável para garantir a vida no planeta, bem como a inclusão social das pessoas. Assim sendo, denota-se que a solução da crise ambiental e a emancipação da opressão ainda vivenciada por grande parte das mulheres do mundo devem ser tratadas como problemas similares, análogos e jamais como questões isoladas. Tanto a manutenção das diversas formas de vida no planeta, como a emancipação dos seres humanos estão vinculados a uma mudança radical na estrutura e na organização da sociedade, baseados na ética da responsabilidade entre os seres humanos, com os animais e com toda a biodiversidade do planeta. 


\section{Referências}

Badinter, E. (1986.) Um é o outro. Relações entre homens e mulheres. Rio de Janeiro: Nova Fronteira.

Beauvoir, S. (1968). Das andere Geschlecht: Sitte und Sexus der Frau. Hamburg: Rowohlt.

Casares, A. (2012). Antropología de Género: culturas, mitos y esterotipos sexuales. Tercera Edición. Universitat de València. Madrid: Ediciones Cátedra Grupo Anaya.

Eagleton, T. (2005). A idéia de Cultura. Tradução Sandra Castello Branco. São Paulo: Editora UNESP.

Ehrenreich, B., english. (1984). Deirdre. Hexen, Hebammen und Krankenschwestern. 11. Auflage. München: Frauenoffensive.

Eisler, R. (2007). O cálice e a espada: nosso passado, nosso futuro. Tradução de Ana Luiza Dantas Borges, Rocco. Rio de Janeiro.

Eisler, R. (1996). O prazer sagrado: sexo, mito e política do corpo. Tradução de Tônia Van Acker. São Paulo: Palas Athena.

Fraser, N. (2007a). Reconhecimento sem ética? Revista Lua Nova. São Paulo, 70, 101-138.

Fraser, N. (2007b, maio-agosto). Mapeando a imaginação feminista. Estudos Feministas. Florianópolis, 15(2), 291-308.

Fraser, N. (2011, Jul-Dez). Mercantilização, proteção social e emancipação: as ambivalências do feminismo na crise do capitalismo. Revista Direito GV. São Paulo, 7(2), 617-634.

Fraser, N. (2010). Redistribuição, Reconhecimento e Participação: Por uma Concepção Integrada da Justiça. In: SARMENTO, Daniel; IKAWA, Daniela; PIOVESAN, Flávia (Orgs.). Igualdade, Diferença e Direitos Humanos. $2^{\mathrm{a}}$ tiragem. Rio de Janeiro: Editora Lumen Juris, p. 167-190.

Gebara, I. (1997). Teologia Ecofeminista. São Paulo: Editora Olho d'Água.

Hall, S. (2005). A identidade Cultural na pós-modernidade. Tradução: Thomaz Tadeu da Silva; Guacira Lopes Louro. Rio de Janeiro: DP\&A editora.

Holland-Cunz, B. (1996). Ecofeminismos. Traducción: Arturo Parada.Madrid: Ediciones Cátedra. 
Revista Universidad en Diálogo • Vol. 7, N. ${ }^{1}$ 1, Enero-Junio 2017, pp. 51-68

ISSN 2215-2849 • EISSN: 2215-4752

DOI: http://dx.doi.org/10.15359/udre.7-1.3

Lagarde y de los Ríos, M. (2011). Los cautiverios de las mujeres: Madresposas, monjas, putas, presas y locas. Madrid: Romanyà Vakks.

Menschik, J. (1977). Feminismus, geschichte, theorie und praxis. Köln: Verlag Pahl Rugenstein.

Mies, M., Shiva, V. (1995). Ökofeminismus. Beiträge zur Praxis und Theorie. Zürich: Rotpunkt-Verlage.

Perrot, M. (2007). Minha história das mulheres. Tradução de Angela M. S. Côrrea. São Paulo: Contexto.

Puleo, A. H. (2002). Feminismo y Ecología. El Ecologista. № 31. Espanha.

Puleo, A H. (2013). Ecofeminismo: para otro mundo posible. Segunda Edición. Valência (Espanha): Ediciónes Cátedra Universitat de València - Instituto de la Mujer, 2013.

Ruether, R R. (1993). Sexismo e Religião: rumo a uma teologia feminina. Tradução de Walter Altmann; Luís Marcos Sander. São Leopoldo, RS: Sinodal.

Yll, E Sanahuja. (2007). La cotidianeidad em la prehistoria: la vida y su sostenimiento. Mujeres, Voces y Propuestas. Barcelona: Icaria Antrazyt. 